\title{
STUDY OF THE POSSIBILITY OF USING LOGGING RESIDUE FOR THE PRODUCTION OF WOOD PROCESSING ENTERPRISES
}

\author{
Mihail Zyryanov, Sergey Medvedev, Aleksandr Mokhirev* \\ Reshetnev Siberian State University of Science and Technology Lesosibirsk, Russian Federation
}

As analysis of the results of numerous studies has shown, the raw material for the production of wood fiber material can be chips from wood residue. In the process of producing high-quality wood fiber semi-finished product, high-quality wood chips are subjected to hydrothermal processing and further grinding in disk blade grinding machines in two stages. Significant energy intensity of the process of wood fiber production is caused not only by the grinding of chips in two steps, but also by overcoming the hydrodynamic resistance of the aquatic environment in which grinding is carried out. In order to solve the problem of expanding the raw material base for the production of wood fiber semi-finished product and reduce the energy intensity of the grinding process, research has been carried out on the process of grinding chips from logging residues in an aerodynamic environment in a modernized plank-cross grinder. An analysis of the features of the process of grinding chips in an aerodynamic environment has been performed and an estimate of its effectiveness has been formed. The influence of the main structural and technological parameters of the process of production a wood fiber semi-finished product in an aerodynamic environment on its quality indicators is shown. Statistical-mathematical equations and graphical dependences are obtained that allow predicting the quality indicators of a wood fiber semi-finished product for given structural and technological parameters of the grinding equipment.

Key words: fibrillation, grinding degree, chips, fiber, logging residues, mathematical model, grinding

\section{INTRODUCTION}

Due to the fact that the need for wood raw materials is constantly increasing, the question of its complex use becomes relevant. Meeting the needs of wood processing industries for raw materials should be carried out both at the expense of economical and the most complete use of wood resources [1]. As a result, one of the main directions of development of the forest complex is to increase the use of all wood material. For that purpose, it is necessary to improve the structure of the production of the timber and woodworking industry further, the improvement of technological processes for the production of technological chips, fiber board, plywood, cardboard and other sawn timber substitutes [2]. One of the priorities of the use of logging residues such as knots, branches and toppings is the production of semi-finished wood fiber [3]. However, it should be noted that traditional grinding technologies and grinding equipment do not allow producing semi-finished wood fiber with the required quality characteristics from the chips left from the processing of logging residues.

\section{EXPERIMENTAL PART}

In order to expand the raw material base for the production of wood fiber semi-finished product and increase the efficiency of the grinding process of phytogenic residue, the plank-cross grinder design was developed at the laboratory of "Forestry and chemical technology" of the Lesosibirsk Branch of Reshetnev Siberian State University [4]. It allows the process of knife-grinding in the aerodynamic environment.
The grinding chamber of the grinding machine is presented in Figure 1.

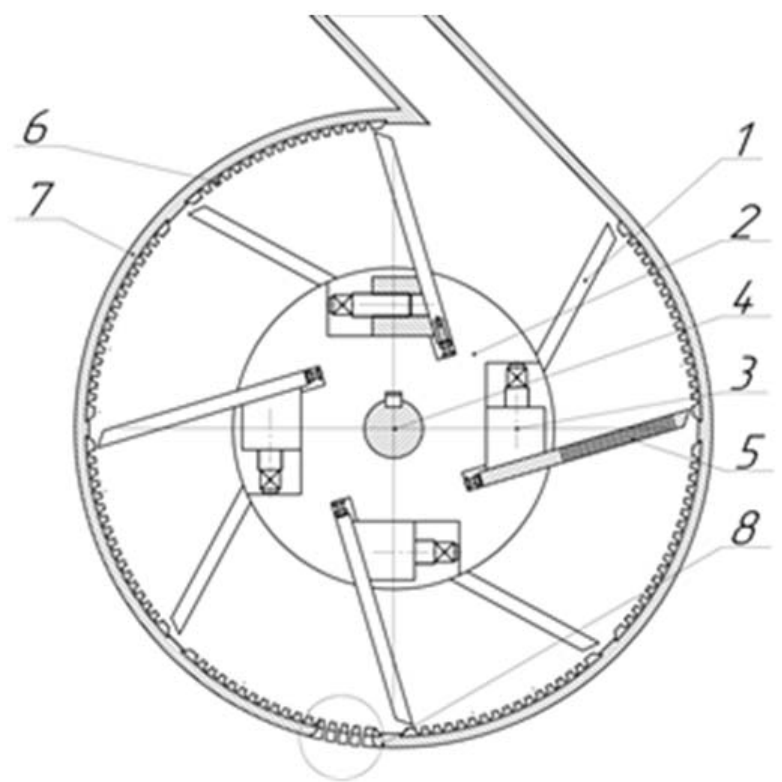

1 - rotor knife; 2 - knife head; 3 - clamping plate; 4 - rotor shaft; 5 - knife openings of rotor knife separators; 6 - corrugated stator strap; 7 - grinding chamber cap; 8 - knives openings of corrugated strap separators

\section{Figure 1: Grinding chamber of a plank cross mill}

Due to the design features of this grinding machine, the raw materials go through four grinding zones during the grinding process. In zone I, grinding is carried out in the working gap between the rotor knives and knives of the 
corrugated stator strap. An intense effect on the fibrous semi-finished product proceeds, which is accompanied by crushing, cutting, crumpling and friction. In the sector between the rotor knives (zone II), the wood fiber mass is mixed due to friction forces and centrifugal force according to aerodynamic laws, which promotes fibrillation of wood fiber [5]. In zone III, located in the area of the base of the rotor knife with knife openings, fibrillation of wood fiber occurs due to sharp teeth in the knife openings. In the inter-knives cells of the corrugated straps (zone IV), fibrillation takes place, the alignment of geometric dimension of the fiber happens, and the fiber is divided into fractions due to the knife openings [6]. Zone IV is the final, wood fiber semi-finished product having the required geometrical dimensions passes through the knife openings and leaves the grinding chamber.

The studies of this work were put into practice using pine (Pinus sylvestris) chips in the form of knots, branches and toppings left from logging residues. In order to weaken the inter-fiber bindings, chip was conditioned with acetic acid aqueous solution before loading in the grinding chamber $[7,8]$.

An active multifactorial experiment was taken as the main method of obtaining a statistical-mathematical description of the process using a second-order B-plan [9, 10].

The following technological and design parameters of the process were selected as input factors for the experiment: $\gamma$ - angle of inclination of the front edge of the knife, degrees; $z$ - the size of the gap, mm; - the exposure time of the chips in acetic acid aqueous solution, min. The levels and intervals of variation of these factors are presented in the table 1.

Table 1: The main factors and the levels of their variation

\begin{tabular}{|c|c|c|c|c|c|c|}
\hline \multirow{2}{*}{$\begin{array}{l}\text { Name of the } \\
\text { factor }\end{array}$} & \multicolumn{2}{|c|}{ Designation } & \multirow{2}{*}{ 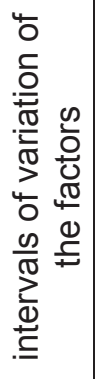 } & \multicolumn{3}{|c|}{$\begin{array}{l}\text { Level of factor } \\
\text { variation }\end{array}$} \\
\hline & 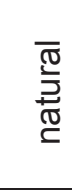 & 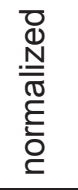 & & 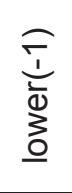 & $\begin{array}{l}\text { อ } \\
\frac{0}{0} \\
\mathbb{0} \\
0\end{array}$ & 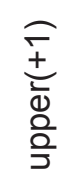 \\
\hline $\begin{array}{l}\text { Angle of } \\
\text { inclination of the } \\
\text { front edge of the } \\
\text { knife }\end{array}$ & Y & $\mathrm{X}_{1}$ & 10 & 30 & 40 & 50 \\
\hline Size of the gap & z & $\mathrm{X}_{2}$ & 0,2 & 0,2 & 0,4 & 0,6 \\
\hline $\begin{array}{l}\text { Exposure time of } \\
\text { the chips in an } \\
\text { acetic } \\
\text { acid aqueous } \\
\text { solution }\end{array}$ & $\mathrm{T}$ & $\mathrm{X}_{3}$ & 10 & 10 & 20 & 30 \\
\hline
\end{tabular}

As controlled factors of the experiment were measured:

- $\quad$ grinding size, DS (defibrator second);

- fractional quality indicator of grinding, Fr.

\section{RESULTS AND DISCUSSION OF EXPERIMENT}

As a result of processing experimental data using modern experimental and laboratory-measuring base at the appropriate level of metrological support of research, equations describing the change in the increase in the grinding size and the fractional quality indicator of grinding from the technological and design parameters of the grinding machine have been obtained.Calculations confirmed that all coefficients of the regression equation are significant.

$$
\begin{aligned}
& D S=21,59-0,25 \cdot \gamma-2,2 \cdot z+1,95 \cdot t+ \\
& +0,44 \cdot \gamma \cdot z-0,19 \cdot z \cdot t-0,31 \cdot \gamma \cdot t- \\
& 0,59 \cdot \gamma^{2}-0,34 \cdot z^{2}-0,09 \cdot t^{2} \\
& F r=33,97+0,31 \cdot \gamma-2,1 \cdot z+1,93 \cdot t+ \\
& 0,34 \cdot \gamma \cdot z-0,09 \cdot z \cdot t-0,16 \cdot \gamma \cdot t- \\
& 0,17 \cdot \gamma^{2}-0,42 \cdot z^{2}+0,03 \cdot t^{2}
\end{aligned}
$$

For clarity and a more complete assessment of the influence of the factors under study on the quality indicators of the wood fiber semi-finished product, response surfaces are constructed using equations 1 and 2 . The response surfaces give a more complete demonstration of the dependence of the quality indicators of the semi-finished wood fiber from the design and technological parameters of the plank-cross mill.

As it can be seen from the presented in fig. 2a, graphical dependencies and equation 1, with an increase in the exposure time of the chips in an aqueous solution of acetic acid, the degree of mass grinding increases. It happens due to the fact that with longer time of exposure of chips in an acetic acid aqueous solution increases the plasticity of the wood. In the future, with the mechanical impact on the wood a large amount of fines is formed. So, when the chips are conditioned in an acetic acid aqueous solution from 18 to 20 minutes, the grinding size of the mass reaches 20-22 DS and tends to increase with longer conditioning.

As it can be seen in the graphical dependence presented in Figure $2 b$, with a decrease in the size of the working gap, there is a tendency to increase the value of the grinding size index. With the size of the working gap of 0.3-0.4 mm, the value of the index of the grinding size of the mass reaches 20-22 DS.

With an increase in the angle of inclination of the front edge of the rotor knife, the value of the index of the grinding size increases and reaches its maximum value of 20-21 DS at $\mathrm{Y}=35-41$ degrees.

Analyzing the graphical dependencies presented in Figure 3 and equation 2, it can be seen that with an increase in the exposure time of chips in an acetic acid aqueous 
(a)
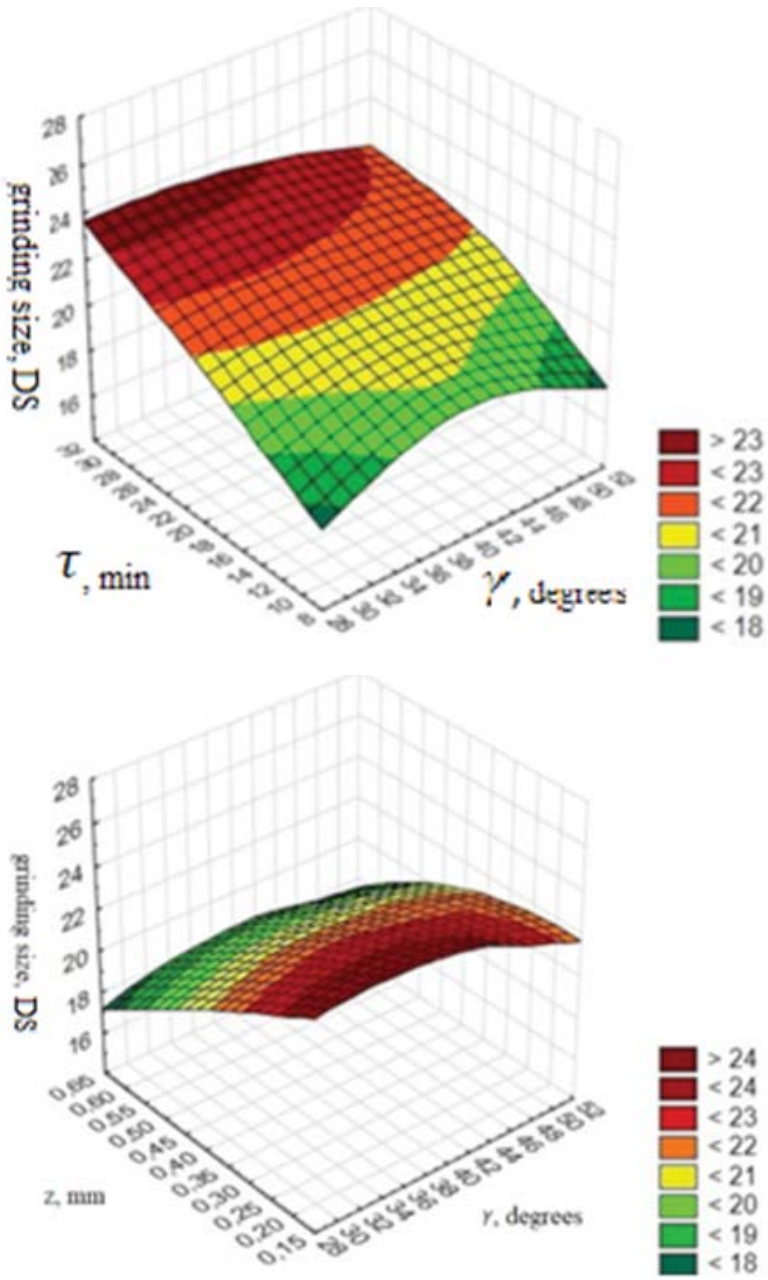

Figure 2: The dependence of the degree of grinding of wood pulp (Pinus sylvestris) from the time of exposure of chips in an acetic acid aqueous solution and the angle of inclination of the front edge of the rotor knife (a) and the size of the working gap and the angle of inclination of the front edge of the rotor knife (b)

solution and a decrease in the value of the size of the working gap, the value of the fractional indicator of the quality of grinding of wood fiber semi-finished products increases.

As the results of the experiment show, the more chips are conditioned in an acetic acid aqueous solution and the smaller the working gap, the more wood fiber semi-finished product contains wood dust and fines, which in turn increases the value of the fractional indicator of the grinding quality. With an increase of the angle of inclination of the front edge of the rotor knife, the value of the fractional indicator of the grinding quality increases and reaches its maximum value of $35-36 \mathrm{~g}$, with $y=35-41$ degrees. With a further increase in the angle of inclination of the front edge of the rotor knife, the value of the fractional indicator of the grinding quality decreases. With an increase in the angle of inclination to the front edge of the rotor knife, the value of the fractional indicator of the grinding quality increases and reaches its maximum value of $35-36 \mathrm{~g}$, with $\mathrm{y}=35-41$ degrees.

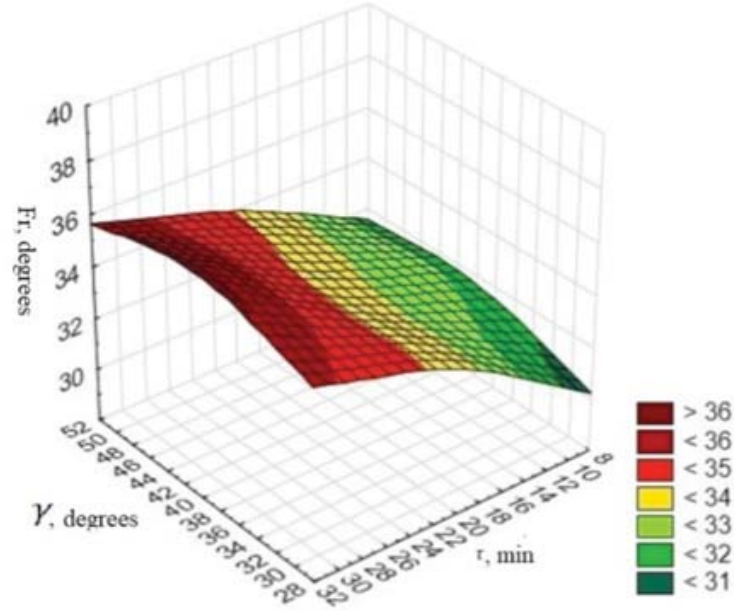

(a)

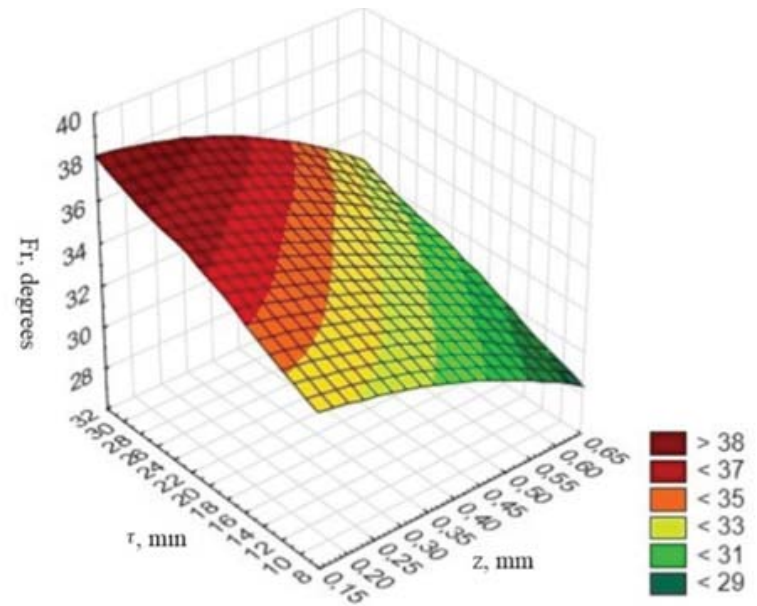

(b)

Figure 3: The dependence of the fractional composition of wood fiber mass from the time of exposure of chips in an acetic acid aqueous solution and the angle of inclination of the front edge of the rotor knife (a) and on the size of the working gap and time of exposure of chips in an acetic acid aqueous solution (b)

With a further increase in the angle of inclination of the front edge of the rotor knife, the value of the fractional indicator of the grinding quality decreases.

\section{CONCLUSION}

Thus, statistical and mathematical equations obtained in during the research and graphical dependencies describing the process of grinding chips from logging residues in a plank-cross grinder make it possible to predict the production of high-quality semi-finished wood fiber, depending on the established modes of the grinding process. The presented research results show that wood chips semi-finished product suitable for further use in the production of structural, finishing and insulating materials can be made from the chips left as a result of processing forest residues.

Using the technology of grinding chips in the aerodynamic environment will significantly reduce the energy intensity of the process of producing wood fiber semi-finished product. 


\section{ACKNOWLEDGEMENT}

The reported study was funded by Russian Foundation for Basic Research, Government of Krasnoyarsk Territory, Krasnoyarsk Regional Fund of Science, to the research project: «Research and modeling of economic development of the forest industry in the region in the context of climatic conditions and resource potential», grant № 18-410-240003, The project «Development and implementation of effective technology for integrated processing of logging residue» was funded by Krasnoyarsk Regional Fund of Science, The study was supported by a grant from the President of the Russian Federation - for young scientists - candidates of sciences MK-1902.2019.6.

\section{REFERENCES}

1. Zyryanov, M.A. (2011). Production of wood fiber semi-finished products in the production of fiber board wet. Wood boards: Theory and practice, pp. 57-61.

2. Bezrukikh, Y.A., Medvedev, S.O., Alashkevich, Y.D., \& Mokhirev, A.P. (2014). Rational natural resources management in the conditions of development industrial enterprises of forestry complex. Economics and Enterprise, No. 12-2; pp. 994-996; http://www. intereconom.com/archive/205.html.

3. Zyryanov, M.A. (2010). Processing of wood residue in production of wood fiber board. Bulletin of KSAU, No. 4; pp. 288-291.
4. Zyryanov, M.A., Chistova, N.G., \& Lazareva, L. (2011). Improving the performance of the grinding section of the production of fiber board wet method. Chemistry of vegetable raw materials, No 3; pp. 193196.

5. Chistova, N.G. (2011). Optimization of the grinding process in the production of fiber board. Forest journal, No. 4; pp. 123-128.

6. Zozulya, V.V., Romanchenko, O.V., Zuykov, A.V., \& et al., (2017). Financial stimulation of forest resources deep processing. Journal of Advanced Research in Law and Economics, T. 8; No 1; pp. 306-312.

7. Goldstein, J. (2002). Finding new markets for local waste wood. BioCycle, T. 43; No 12; pp. 30.

8. Mokhirev, A., Zyryanov, M., Ryabova, T., \& Vititnev, A. [2019]. Evaluation of possibility of obtaining woodchips from wood residues. Journal of Applied Engineering Science, 17(2), 140-143.

9. Zyryanov, M.A., Dresvyankin, I.A., \& Rubinskaya, A.V. (2016). Experimental theoretical substantiation of physical and chemical transformations of wood biomass in the production technology of fiber board. Engineering Bulletin of the don, No 4; ivdon.ru/ru/ magazine/archive/n4y2016/3841.

10. Hellen, E. (2011). Beyond Paper and board - leap in resource-efficiency with nanocellulose and new forming techniques. In Forestcluster Ltd's annual seminar - Helsinki. $25 \mathrm{p}$. 